\title{
Prevalence of Worsening Problems Using Post-stroke Checklist and Associations with Quality of
}

\section{Life in Patients with Stroke}

Hyowon Im, MD ${ }^{1 \dagger}$,Won-Seok Kim, MD, $\mathrm{PhD}^{1,2+^{*}}$, SeungYeun Kim, MD ${ }^{1}$, Ji-Hong Park, MD ${ }^{1}$, Nam-Jong Paik, MD, $\mathrm{PhD}^{1,2^{*}}$

${ }^{1}$ Department of Rehabilitation Medicine, Seoul National University College of Medicine, Seoul National University Bundang Hospital, Seongnam, Korea

${ }^{2}$ Gyeonggi Regional Cardiocerebrovascular Center, Seoul National University Bundang Hospital, Seongnam, Korea

${ }^{\dagger}$ These authors contributed equally to this work.

\section{"Correspondence:}

Nam-Jong Paik, MD, PhD.

Department of Rehabilitation Medicine, Seoul National University College of Medicine,

Seoul National University Bundang Hospital, 82, Gumi-ro 173 Beon-gil, Bundang-gu, Seongnam 463707, Korea

Tel: +82-31-787-7731 Fax: +82-31-712-3913 E-mail: njpaik@snu.ac.kr

Won-Seok Kim, MD, PhD.

Department of Rehabilitation Medicine, Seoul National University College of Medicine,

Seoul National University Bundang Hospital, 82, Gumi-ro 173 Beon-gil, Bundang-gu, Seongnam 463707, Korea

Tel: +82-31-787-7735, Fax: +82-31-787-4051, E-mail: wondol77@gmail.com 
Other co-authors' email addresses

Hyowon Im, MD: remire@ hanmail.net

SeungYeun Kim, MD: seungyeun@hanmail.net

Ji-Hong Park, MD: parkjihong.md@gmail.com 


\begin{abstract}
Background: This study investigated the prevalence of worsening problems using Post Stroke Checklist (PSC) at 3, 6, and 12 months post-stroke and their associations with health-related quality of life.
\end{abstract}

Methods: In stroke patients admitted between June 2014 and December 2015, PSC and EuroQol5Dthree level (EQ-5D-3L) were assessed at post-stroke $3(n=181), 6(n=175)$, and 12months $(n=89)$. The prevalence of worsening problems and its association withEQ-5D-3L at post-stroke 3 and 6 months were analyzed.

Results: An average of 0.59 (range 0-12), 1.47 (range 0-12), and 1.00 (range 0-10) worsening problems per patient was identified at 3,6 , and 12 months after stroke, respectively. The most frequently and continuously identified worsening problems were mood disturbances (reported by $8.8 \%, 16.0 \%$ and $13.5 \%$ of patients at 3,6 , and 12 months post-stroke, respectively). Worsening mobility was significantly associated with worse EQ-5D index at post-stroke 3 months $(\beta,-0.583 ; 95 \% \mathrm{CI},-1.045$ to -0.120). The worsening of mobility and communication was significantly associated with worse EQ5D index at post-stroke 6 months (mobility: $\beta,-0.170$; $95 \%$ CI, -0.305 to -0.034 , communication: $\beta,-$ $0.164 ; 95 \%$ CI, -0.309 to -0.020$)$.

Conclusions: PSC may be useful for the detection of various subjective worsening problems during serial clinical follow-up after stroke. Appropriate rehabilitation and management strategy to solve the identified problems could improve the quality of life in stroke survivors.

Key Words : Rehabilitation, Stroke, Long-term care, Quality of life, Post-stroke checklist, Unmet needs 


\section{Background}

Stroke is the most common cause of adult disability worldwide [1, 2]. Stroke survivors suffer from various kinds of motor and non-motor problems, which impact poor participation [3, 4]. Without proper resolution of these problems, they can result in worsening of health-related quality of life (HRQoL) [5]. However, long-term post-stroke care has not been standardized yet [6], and stroke survivors have reported that health systems are not responsive to their changing needs [7]. Therefore, long-term stroke follow-up should address a broad range of post-stroke medical and HRQoL-related problems with scheduled reassessments.

To improve the standard of long-term management and HRQoL for stroke survivors, a post-stroke checklist (PSC) was developed by the Global Stroke Community Advisory Panel [3]. Eleven post-stroke problem areas were chosen through the Delphi process [3]. These areas are: secondary prevention, activities of daily living, mobility, spasticity, pain, incontinence, communication, mood, cognition, life after stroke, and relationship with caregiver. The major purpose of PSC application was to identify which areas could be managed by appropriate intervention and which area could have significant impact on HRQoL by these interventions [3].

Although a previous clinical pilot study demonstrated the feasibility and usefulness of PSC practice in the United Kingdom and Singapore [4], to the best of our knowledge, the association between identified problems in PSC and HRQoL with consideration of the objective functional outcomes as confounding variables has not been investigated yet. Hence, the aim of this study was to investigate the prevalence of worsening problems at 3,6, and 12 months post-stroke and their associations with HRQoL in patients with stroke.

\section{Methods}

\section{Subjects}


A total of 197 patients who were diagnosed as stroke and admitted to Seoul National University Bundang Hospital between June 2014 and December 2015 were enrolled in this study (Figure 1). All patients were evaluated for functional states before discharge, and the median length of hospital stay was 24 days (interquartile range [IQR], 18-32).

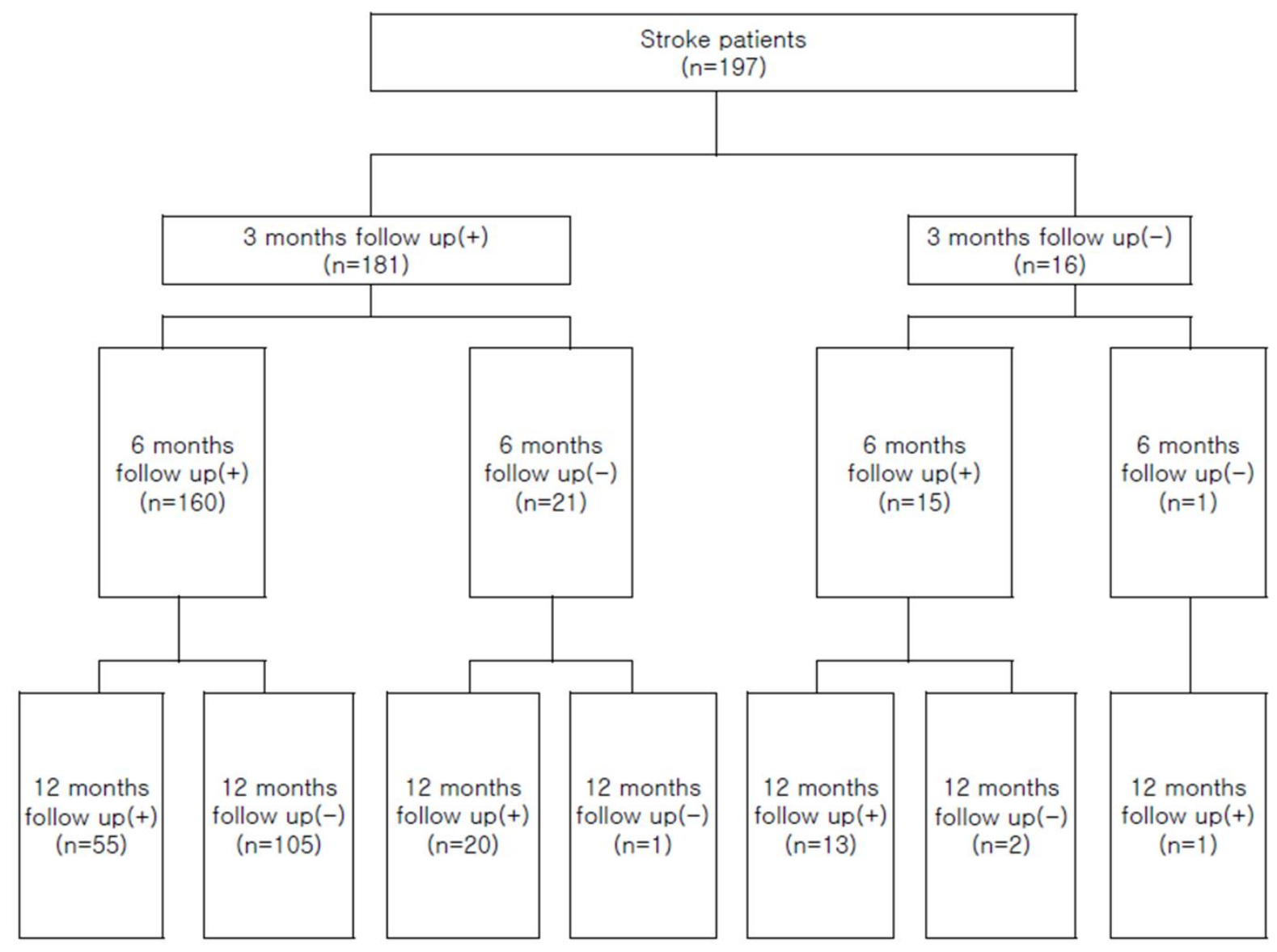

Figure 1. Flow chart of subjects involved in the study. 16 patients could not enrolled (absence when telephone interview: 15, refusal to interview: 1). At post-stroke 6 months, total 192 patients were assessed, and 17 patients were excluded (absence when telephone interview: 16, refusal to interview: 1). At post-stroke 12 months, total 106 patients were assessed, and 17 patients were excluded (absence when telephone interview: 13 , refusal to interview: 3 , death: 1) 


\section{Baseline Measurements}

The baseline characteristics, such as sex, age, years of education, and marital state, as well as clinical information, such as the type of stroke (ischemic or hemorrhagic), lesion of stroke (cortical or subcortical), and comorbidities (e.g., hypertension, diabetes mellitus, cardiovascular disease, chronic lung disease, malignancy and previous central nervous system injury) were obtained from medical chart review by a physician. The severity of the stroke was assessed with the National Institutes of Health Stroke Scale (NIHSS) [8]. The Korean version of Modified Barthel Index (K-MBI) [9] was used to measure the dependency in activities of daily living. Cognitive function was measured by the Korean Mini-Mental State Examination (K-MMSE) [10] and the Korean version of the Clinical Dementia Rating (CDR) [11]. All measurements aforementioned were assessed within a week before discharge.

\section{Survey during the follow-up}

A survey was used to conduct this study at post-stroke 3, 6, and 12 months. PSC, EuroQol-5D three level (EQ-5D-3L) [12, 13], functional ambulation category (FAC) [14], modified Rankin Scale (mRS) [15], and continuation of rehabilitation and residency (home vs. others (e.g. hospitals, nursing home)) were assessed at the time of a follow-up interview (3, 6 and 12 months after stroke). Each item of PSC was comprised of a dichotomous, 'yes' or 'no' response scale. We used the Korean version of the EQ5D-3L index [16]. The EQ-5D index was calculated using the Korean valuation set [17]. In outpatient follow-up, if the patient was unable to complete the self-questionnaire due to cognitive impairment, the questionnaire was filled out by a proxy. Patients who did not visit the clinic for follow-up were interviewed via telephone. The interviews were conducted by a trained research assistant.

Statistical Analysis 
The differences of baseline characteristics with continuous variables between the groups at each follow-up time point were analyzed using analysis of variance with post-hoc analysis using Bonferroni's test. In the categorical variables, a Chi-square test was performed to investigate group differences.

Univariate analyses (student's t-test for continuous variables, Chai-square test for categorical variables) were performed with the EQ-5D index at post-stroke 3months or 6monthsas a dependent variable. Independent variables included were the baseline characteristics - age, years of education, sex, marital state, interviewee, continuation of rehabilitation, NIHSS, K-MBI, mRS, FAC, K-MMSE, CDR - and follow-up variables measured at 3 or 6 months after stroke, including FAC, mRS, and all items of PSC, except the item for secondary prevention.

The stepwise multiple linear regression was performed with significant variables in univariate analyses $(P$ value $<0.05)$ at each follow-up time point (post-stroke 3 or 6 month) with entry condition of $P$ value $<0.05$ and removal condition of $P$ value $>0.10$. Finally, factors well-known to have an impact on HRQoL, such as age, sex, NIHSS at discharge, follow-up mRS and FAC [18-21], and other factors that demonstrated significant associations with EQ-5D-3L $(P$ value $<0.05)$ at specific follow-up time points (post-stroke 3 or 6 month) in the stepwise multiple linear regression were included in the final multiple linear regression model by the enter method.

Correlations between the EQ-5D index and FAC or mRS at post-stroke 6 months were evaluated with Spearman's correlation analysis, which was performed in each of the two groups according to the interviewee (patients themselves vs. proxy). All analyses were conducted using SPSS, Version 19.0 (IBM Co., Armonk, NY, USA).

\section{Results}

\section{Subject characteristics}


A total of 181,175 , and 89 patients at 3, 6, and 12 months after stroke, respectively, were assessed using PSC and EQ-5D-3L. Figure 1 demonstrates the flow of subject enrollment.

The baseline characteristics assessed at discharge are presented in Table 1. The mean age of patients was 67.3 years, 68.5 years, and 65.1 years at 3, 6, and 12 months after stroke, respectively. Male had slightly higher proportion than female in all of the follow-up periods (3 months: 54.1\%, 6 months : $57.1 \%, 12$ months : 53.9\%, respectively). Between the three different time points, no statistically significant differences were found for all variables (Table 1).In the follow-up periods, the mean of the EQ-5D index was $0.68,0.65$, and 0.69 at 3,6 , and 12 months after stroke, respectively. The percentage of patients who stayed at home was the highest at 12 months ( 3 months : 39.9\%, 6 months : 52.7\%, 12 months : $57.1 \%$, respectively) (Table 2). 
Table 1. Baseline characteristics of subjects who participated in the post-stroke checklist

\begin{tabular}{|c|c|c|c|c|}
\hline & $\begin{array}{l}3 \text { months } \\
(n=181)\end{array}$ & $\begin{array}{l}6 \text { months } \\
(n=175)\end{array}$ & $\begin{array}{r}12 \text { months } \\
(n=89)\end{array}$ & $P$ value \\
\hline Age, years* & $67.3(13.0)$ & $68.5(12.5)$ & $65.1(13.6)$ & $0.138 *$ \\
\hline \multicolumn{5}{|l|}{ Sex, n (\%) } \\
\hline Male & $98(54.1 \%)$ & $99(56.6 \%)$ & $48(53.9 \%)$ & $0.865 \S$ \\
\hline Female & $83(45.9 \%)$ & $76(43.4 \%)$ & $41(46.1 \%)$ & $0.865 \S$ \\
\hline Interviewee, n (\%) & & & & $0.438 \S$ \\
\hline Patient & $46(33.8 \%)^{\dagger \dagger \dagger}$ & $61(39.9 \%)^{+1}$ & $34(41.5 \%)^{\S \S \S}$ & \\
\hline Caregiver & $90(66.2 \%)$ & $92(60.1 \%)$ & $48(58.5 \%)$ & \\
\hline Length of hospital stay $\dagger$ & $23(17-32)$ & $23(17-31)$ & $24(18-32)$ & $0.249 \ddagger$ \\
\hline Stroke, type, n (\%) & & & & $0.774 \S$ \\
\hline Ischemic & $132(72.9 \%)$ & $133(76.0 \%)$ & $62(69.7 \%)$ & \\
\hline Hemorrhagic & $47(26.0)$ & $39(22.3 \%)$ & $25(28.1 \%)$ & \\
\hline Combined & $2(1.1 \%)$ & $3(1.7 \%)$ & $2(2.2 \%)$ & \\
\hline Stroke, lesion, n (\%) & & & & $0.721 \S$ \\
\hline Cortical & $64(35.4 \%)$ & $63(36.0 \%)$ & $26(29.2 \%)$ & \\
\hline Subcortical & $111(61.3 \%)$ & $108(61.7 \%)$ & $59(66.3 \%)$ & \\
\hline Combined & $6(3.3 \%)$ & $4(2.3 \%)$ & $4(4.5 \%)$ & \\
\hline \multicolumn{5}{|l|}{ Comorbidities, n (\%) } \\
\hline Hypertension & $109(60.2 \%)$ & $103(58.9 \%)$ & $56(62.9 \%)$ & $0.717 \S$ \\
\hline Diabetes mellitus & $50(27.6 \%)$ & $46(26.3 \%)$ & $24(27.0 \%)$ & $0.942 \S$ \\
\hline Cardiovascular disease & $42(23.2 \%)$ & $41(23.4 \%)$ & $24(27.0 \%)$ & $0.770 \S$ \\
\hline Chronic lung disease & $5(2.8 \%)$ & $5(2.9 \%)$ & $4(4.5 \%)$ & $0.775 \S$ \\
\hline Malignancy & $13(7.2 \%)$ & $12(6.9 \%)$ & $7(7.9 \%)$ & $0.971 \S$ \\
\hline
\end{tabular}


Previous CNS injury

$31(17.1 \%) \quad 34(19.4 \%)$

$19(21.3 \%)$

$0.678 \S$

Discharge place, n (\%)

Acute care hospital

Chronic care hospital

Rehabilitation hospital

Nursing home

Home care program

Home

Years of Education*

Korean Medicaid

\section{Marital status}

Married

Widowed

Single

FAC $\uparrow$

mBI*

$\mathbf{m R S} \dagger$

NIHSS*

MMSE*

CDR $\dagger$

$\begin{array}{lrrr}7(3.9 \%)^{\|} & 5(2.9 \%)^{\mathrm{I}} & 4(4.5 \%) & 0.847 \S \\ 16(8.8 \%)^{\|} & 15(8.6 \%)^{\mathrm{I}} & 10(11.2 \%) & 0.772 \S\end{array}$

$84(46.4 \%)^{\|} \quad 85(48.6 \%)^{\mathrm{I}} \quad 44(49.4 \%) \quad 0.894 \S$

$20(11.0 \%)^{\|} \quad 17(9.7 \%)^{\mathrm{q}} \quad 12(13.5 \%) \quad 0.669 \S$

$\begin{array}{llll}4(2.2 \%)^{\|} & 6(3.4 \%)^{\mathrm{I}} & 2(2.2 \%) & 0.748 \S\end{array}$

$49(27.1 \%)^{\|} \quad 46(26.3 \%)^{\mathbb{\Psi}} \quad 17(19.1 \%) \quad 0.323 \S$

$10.8(4.5) \quad 10.6(4.4) \quad 10.7(4.6) \quad 0.916 \ddagger$

$7(3.9 \%) \quad 8(4.6 \%) \quad 5(5.6 \%) \quad 0.922 \S$

$141(77.9 \%) \quad 137(78.3 \%) \quad 78(87.6 \%)$

$30(16.6 \%) \quad 29(16.6 \%) \quad 6(6.7 \%)$

$10(5.5 \%) \quad 9(5.1 \%) \quad 5(5.6 \%)$

$2(0-3)^{* *} \quad 2(0-2)^{\mathbb{I}} \quad 2(0-3)^{\dagger \dagger} \quad 0.973 \ddagger$

$53.6(31.2)^{\|} \quad 52.2(31.4)^{\mathscr{I}} \quad 56.0(31.7)^{\S \S} \quad 0.645 \ddagger$

$3(3-4) \quad 3(3-4) \quad 3(3-4) \quad 0.605 \ddagger$

$\begin{array}{llll}6.0(5.0)^{\#} \quad 6.1(5.2)^{\|\|} \quad 5.9(4.9)^{\text {III }} & 0.943 \ddagger\end{array}$

$21.5(9.5)^{\mathbb{q}} \quad 21.2(9.7)^{\|\|} \quad 21.3(9.4)^{\text {IIUI }} \quad 0.949 \ddagger$

$0.5(0-1)^{\#} \quad 0.5(0-1)^{\|\|} \quad 0.5(0-1)^{\# \#} \quad 0.864 \ddagger$

\footnotetext{
*Mean (SD). †Median (IQR).

†ANOVA; §Kruskal-wallis analysis, Fisher’s exact test

$\|n=180 . \rrbracket n=174 . \quad \# n=173 . * * n=179 . \quad \dagger+n=87 . \quad \S \S n=88.\| \quad \| n=166 . \quad \llbracket \llbracket n=85 . \# \# n=83 . \quad \dagger \dagger+n=136$.

$++\downarrow=153 . \S \S \S n=82$
} 
FAC : Functional Ambulation Categories; MBI : Modified Barthel Index; mRS : Modified Rankin Scale; NIHSS : National Institutes of Health Stroke Scale; MMSE : Mini Mental State Examination; CDR : Clinical Dementia Rating

Table 2. Follow-up data including PSC, EQ-5D-3L, mRS, FAC and current residence

3 months $(n=181) \quad 6$ months $(n=175) \quad 12$ months $(n=89)$

\begin{tabular}{|c|c|c|c|}
\hline Identified problems by PSC* & $0.59(1.602)$ & $1.47(2.421)$ & $1.00(2.062)$ \\
\hline EQ-5D-3L* & $0.68(0.31)$ & $0.65(0.32)$ & $0.69(0.33)$ \\
\hline $\mathrm{FAC} \dagger$ & $3.00(1.75-4.00)^{\ddagger}$ & $4.00(1.50-5.00)^{\S}$ & $4.00(1.00-5.00)^{\|}$ \\
\hline $\mathrm{mRS} \dagger$ & $4.00(1.00-5.00)^{\uparrow}$ & $3.00(1.00-4.00)^{\#}$ & $2.00(1.00-4.00)^{* *}$ \\
\hline Stayed at home, n (\%) & $67(39.9 \%)^{\dagger \dagger}$ & $69(52.7 \%)^{\dagger}$ & $40(57.1 \%)^{\|}$ \\
\hline $\begin{array}{l}\text { Continuation of rehabilitation, } \mathrm{n} \\
(\%)\end{array}$ & $73(40.3 \%)^{* *}$ & $36(20.6 \%)$ & $30(33.7 \%)$ \\
\hline
\end{tabular}

*Mean (SD). †Median (IQR).

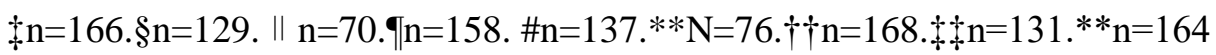

PSC : PostStroke Checklist; EQ-5D-3L:EuroQol-5D three level ; FAC : Functional Ambulation Categories; mRS : Modified Rankin Scale; 


\section{Prevalence of worsening problems}

An average of 0.59 (range $0-12$ ), 1.47 (range $0-12$ ), and 1.00 (range $0-10)$ problems per patient was identified at 3,6, and 12 months post-stroke, respectively (Table 2). The prevalence of each worsening problem is shown in Figure 2. The percentage of worsening problems reported in 6 months or 12 months after stroke was higher than 3 months after stroke for all items. The most commonly aggravating problem in 3 and 12 months after stroke was 'mood', which was 'mobility' in 6 months after stroke. The proportion of worsening spasticity in 6 and 12 months was more than doubled from the prevalence in 3 months. The rate of reporting deterioration of 'ADL', 'mobility', 'pain', 'incontinence', 'communication', 'mood', 'cognition', 'life after stroke', and 'relationship with family' increased until post-stroke 6 months, but decreased in post-stroke 12 months. Among them, 'pain', 'communication', and 'life after stroke' were about twice as high at post-stroke 6 months compared with post-stroke 3 months and 12 months.

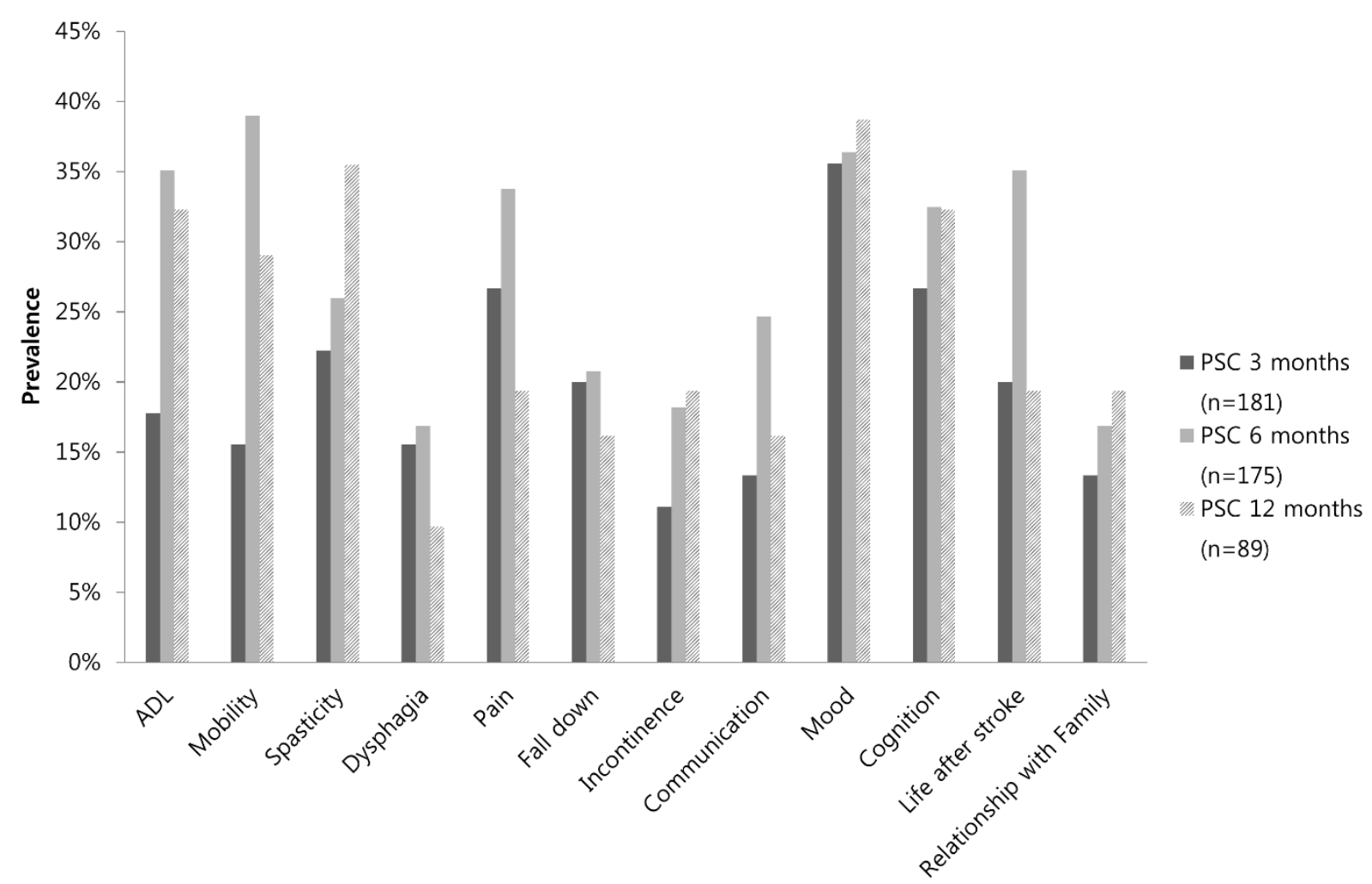

Figure 2. Prevalence of worsening problems for each PSC item following 3, 6, and 12 months. 
Abbreviations: PSC, PostStroke Checklist; ADL, Activities of Daily Living

A number expressed as a percentage is the percentage of case which means the percentage by selecting the corresponding item from among all the respondents.

Factors associated with post-stroke HRQoL

The multiple linear regression analysis demonstrated that the subjective worsening in the mobility at post-stroke 3 months was significantly associated with lower the EQ-5D index at post-stroke 3 months $\left(\beta=-0.583,95 \%\right.$ CI:-1.045--0.120, $\left.\mathrm{R}^{2}=0.491\right)($ Table 3). At post-stroke 6 months, the worsening in the mobility and the communication was significantly associated with lower the EQ-5D index (mobility: $\beta,-0.170 ; 95 \% \mathrm{CI},-0.305$ to -0.034 , communication: $\beta,-0.164 ; 95 \% \mathrm{CI},-0.309$ to $\left.-0.020, \mathrm{R}^{2}=0.666\right)$ (Table 3). In addition, FAC at post-stroke 3 and 6 months showed significant association with the EQ5D index at each follow-up period (post-stroke 3 months: $\beta, 0.095 ; 95 \% \mathrm{CI}, 0.055$ to 0.134 , post-stroke 6 months: $\beta, 0.118 ; 95 \%$ CI, 0.070 to 0.167 ) (Table 3 
Table 3. Multiple linear regression for health related quality of life in post-stroke 3 and 6 months

\begin{tabular}{|c|c|c|c|c|c|c|}
\hline \multirow[b]{2}{*}{ Variables } & \multicolumn{3}{|c|}{ Post-stroke 3 months $(\mathrm{n}=181)$} & \multicolumn{3}{|c|}{ Post-stroke 6 months $(\mathrm{n}=175)$} \\
\hline & $\beta \pm \mathrm{SE}$ & $95 \% \mathrm{CI}$ & $P$ value & $\beta \pm \mathrm{SE}$ & $95 \% \mathrm{CI}$ & $P$ value \\
\hline Sex & $-.058 \pm 0.045$ & $-0.148-0.032$ & 0.203 & $-0.011 \pm 0.04$ & $-0.091-0.069$ & 0.786 \\
\hline Age & $0.002 \pm 0.002$ & $-0.001-0.006$ & 0.157 & $0 \pm 0.002$ & $-0.003-0.004$ & 0.84 \\
\hline NIHSS at discharge & $0.003 \pm 0.005$ & $-0.008-0.013$ & 0.642 & $-0.001 \pm 0.004$ & $-0.009-0.008$ & 0.888 \\
\hline $\mathrm{mRS}$ at 3 months & $-.019 \pm 0.026$ & $-0.07-0.033$ & 0.471 & $0.01 \pm 0.026$ & $-0.042-0.061$ & 0.714 \\
\hline FAC at 3 months & $0.095 \pm 0.02$ & $0.055-0.134$ & $<0.001$ & $0.118 \pm 0.025$ & $0.07-0.167$ & $<0.001$ \\
\hline \multicolumn{7}{|l|}{ PSC item } \\
\hline Mobility & $-.582 \pm 0.233$ & $-1.045--0.12$ & 0.014 & $-0.17 \pm 0.068$ & $-0.305--0.034$ & 0.014 \\
\hline Pain & & & & $-0.117 \pm 0.065$ & $-0.246-0.012$ & 0.075 \\
\hline Communication & & & & $-0.164 \pm 0.073$ & $-0.309--0.02$ & 0.026 \\
\hline
\end{tabular}

3 poststroke 3 months; $\mathrm{R}^{2}=0.491$, Adjusted $\mathrm{R}^{2}=0.462$, poststroke 6 months; $\mathrm{R}^{2}=0.666$, Adjusted $\mathrm{R}^{2}=0.639$

4 NIHSS : National Institutes of Health Stroke Scale; mRS : Modified Rankin Scale; FAC : Functional Ambulation Categories; PSC : Post-stroke Checklist 
Correlation between the EQ-5D index and FAC or mRS according to the interviewee

In the respondent group, better mRS and FAC at post-stroke 6 months were significantly associated with higher EQ-5D-3Lat post-stroke 6 months ( $r=-0.504, P<0.001 ; r=0.484, P=0.01$, respectively). These associations were also similar in the proxy-respondent group: better mRS and FAC at post-stroke 6 months were significantly associated with higher EQ-5D-3Lat post-stroke 6 months $(r=-0.48$, $P<0.001 ; r=0.671, P<0.001$, respectively).

\section{Discussion}

To the best of our knowledge, this is the first study investigating the prevalence of worsening problems using PSC and their associations with HRQoL throughout long-term serial follow-up after stroke. Various worsening problems were reported here (Figure 2), and subjective worsening in mobility or communication were associated with poor HRQoL (Table 3).

The prevalence of subjective worsening problems in all domains dramatically increased at poststroke 6 months (Figure2). The prevalence of deterioration of 'ADL', 'mobility', and 'communication' increased at post-stroke 6 months by more than three times. Because motor, speech, and cognitive functions after stroke usually improve within the first 12 months after stroke [22], the increase in the prevalence of worsening problems at post-stroke 6 months was not expected. One possible explanation is the environmental changes from post-stroke 3 months to 6 months; there were a great deal of patients who were discharged from post-stroke 3 months ( $39.9 \%$ at home) to 6 months $(52.7 \%$ at home) in this study. During hospital stay, patients and caregivers do not fully understand their ability to ambulate, self-care, and communicate; their difficulties may not become fully apparent until they are discharged, in which point in time, they subjectively feel that their ability to deal with these problems is worsening [23]. Therefore, assessment and education to promote adaptation and recovery after stroke, considering the needs of stroke patients and their families in their home environment, should be provided prior to 
discharge $[24,25]$.

Among the various subjective worsening problems, depressive mood was the most common, regardless of the time of evaluation (reported by $8.8 \%, 16.0 \%$ and $13.5 \%$ of patients at 3,6 and 12 months post-stroke, respectively) (Figure 2). Post-stroke depression, which as a prevalence of up to $30 \%$, can occur at any time after stroke [26], and is associated with increased disability, cognitive impairment, mortality, and worse rehabilitation outcome [27-29]. Therefore, efforts to detect mood changes in stroke patients and timely intervention, including antidepressants, should be made to minimize the deteriorative effects of depression [30].

Spasticity showed increased aggravation until 12 months after stroke, which is compatible with previous epidemiologic studies showing that the prevalence and severity of spasticity increases over time after stroke (Figure 2) [31,32]. Because worsening of spasticity is associated with various harmful outcomes (e.g. pain, contractures, poor recovery), serial monitoring of occurrence or aggravation of spasticity and adequate treatments, including stretching, medication, or chemodenervation according to the severity and distribution of spasticity, should be considered [33].

The prevalence of subjective worsening of mobility dramatically increased at 6 months after stroke (Figure 2) and was associated with worse HRQoL (Table 3). In our study, more patients were discharged and returned home at post-stroke 6 months, confronting the real environment and challenges of mobility. Patients should adapt to diverse and complex conditions, including walking on varying terrains (uneven, slippery), in diverse ambient conditions (adverse weather, low light) with attentional demands (distracting environments) [34]. Community ambulation is also influenced by subjective factors such as fear of falling [35]. Limited community ambulation following stroke is associated with poor HRQoL [34]. Therefore, the assessments of ambulatory ability in accordance in each individual's need and individualized training or education should be considered. In addition to the gait function, communication ability is one of the influential factors impacting HRQoL after stroke [36]. Our study also demonstrated that, the subjective deterioration of communication has a significant impact on 
HRQoL in post-stroke 6 months (Table 3). Because basic life activities (such as using a phone, dealing with money, reading and writing administrative documents, etc.) could become difficult by communication problems [37], it is expected for HRQoL to decrease with decreased communication skills.

There are some limitations to this study. First, the proportion of proxy responders was high. Although patient-proxy agreement in post-stroke EQ-5D-3Lhas been reported [38-40], a few studies have suggested that proxies may report inaccurate responses, reporting more disabilities or lower quality of life than the patients themselves [41-43]. In our study, overall disability and mobility significantly correlated with the EQ-5D index reported by both the proxy and patient, suggesting that proxies' assessment of patient's HRQoL was close to the patient's actual disability level. Second, the sample size was decreased due to follow-up loss, especially in post-stroke 12 months. A Multiple regression analysis for HRQoL could not be performed in this period. Third, the EQ-5D index, FAC, and mRS were evaluated by telephone survey. In spite of the limitation of the telephone survey, we made efforts to overcome possible shortcomings. The simplified MRS validated for a telephone survey was used in this study. ${ }^{44}$ Standardized training and manuals for telephone survey were used for EQ-5D and FAC, which have been commonly used in previous telephone survey studies [45-47].

\section{Conclusions}

PSC may be useful for detecting various subjective worsening problems during serial clinical followup after stroke. Appropriate rehabilitation and management strategy to solve the identified problems according to the individual needs at various times after stroke, could improve the HRQoL in stroke survivors. Further study is required to prove the efficacy of these approaches.

\section{List of abbreviations}


CDR: Clinical Dementia Rating, EQ-5D-3L: EuroQol-5D three level, FAC: Functional Ambulation Category, HRQoL: Health-Related Quality of Life, K-MMSE: Korean Mini-Mental State Examination, K-MBI: Korean version of Modified Barthel Index, NIHSS: National Institutes of Health Stroke Scale, PSC: Post-Stroke Checklist

\section{Declarations}

\section{-Ethics approval and consent to participate}

The study was conducted in accordance with the regulatory standards of Good Clinical Practice and the Declaration of Helsinki (World Medical Association Declaration of Helsinki: Ethical Principles for Medical Research Involving Human Subjects, 2008) and was approved by the Seoul National University Bundang Hospital Institutional Review Board (IRB No. B-1607/355-107). The consent to participate was exempted due to the retrospective design of this study.

\section{-Consent for publication}

Not applicable.

\section{-Availability of data and material}

Patients information cannot be shared.

\section{-Competing interests}

The authors declare that they have no competing interests. 


\section{-Funding}

This study was supported by the Seoul National University Bundang Hospital Research Fund (grant number: 06-2017-135).

\section{-Authors' contributions}

HWI obtained the data, performed statistical analysis, and wrote the manuscript. WSK designed the study, interpreted the data, drafted and edited the article and prepared the final version. NJP design the study and critically reviewed the manuscript. SYK assisted with data collection, helped with statistical analysis and reviewed the manuscript. JHP supervised the statistical analysis and reviewed the manuscript.

\section{•Acknowledgements}

We thank Medical Research Collaborating Center (MRCC) of Seoul National University Bundang Hospital for their assistance with statistical analysis.

\section{Reference}

1. Mathers CD and Loncar D. Projections of global mortality and burden of disease from 2002 to 2030. PLoS Med. 2006 Nov;3:e442.

2. Barker-Collo S, Feigin VL, Parag V, et al. Auckland Stroke Outcomes Study. Part 2: Cognition and functional outcomes 5 years poststroke. Neurology. 2010;75: 1608-16. 
3. Philp I, Brainin M, Walker MF, Ward AB, Gillard P, Shields AL, Norrving B. Development of a poststroke checklist to standardize follow-up care for stroke survivors. J Stroke Cerebrovasc. 2013;22:e173-180.

4. Ward AB, Chen C, Norrving B, Gillard P, Walker MF, Blackburn S, Holloway L, Brainin M, Philp I. Evaluation of the Post Stroke Checklist: a pilot study in the United Kingdom and Singapore. Int J Stroke. 2014;9(SA100):76-84.

5. Tistad M, Tham K, von Koch L, Ytterberg C. Unfulfilled rehabilitation needs and dissatisfaction with care 12 months after a stroke: an explorative observational study. BMC neurology. $2012 ; 12: 40$.

6. Rudd AG, Bowen A, Young GR, James MA. The latest national clinical guideline for stroke. Clinical medicine. 2017;17:154-5.

7. White JH, Magin P, Pollack MR. Stroke patients' experience with the Australian health system: a qualitative study. Can J Occup Ther. 2009;76:81-9.

8. Brott T, Adams HP, Olinger CP, Marler JR, Barsan WG, Biller J, Spilker J, Holleran R, Eberle R, Hertzberg V. Measurements of acute cerebral infarction: a clinical examination scale. Stroke. 1989;20:864-70.

9. Jung HY PB, Shin HS, Kang YK, Pyun SB, Paik NJ, Kim SH, Kim TH, Han TR. Development of the Korean Version of Modified Barthel Index (K-MBI): Multi-center Study for Subjects with Stroke. J Korean Acad Rehabil Med. 2007;31:283-97.

10. Kang YW ND, Han SH. A Validity study on the Korean Mini-Mental State Examination (KMMSE) in dementia patients. J Korean Neurol Assoc. 1997;15:300-8. 
11. Choi SH ND, Lee BH, Hahm DS, Jeong JH, Yoon SJ, Yoo KH, Ha CK, Han IW. Estimating the Validity of the Korean Version of Expanded Clinical Dementia Rating (CDR) Scale. J Korean Neurol Assoc. 2001;19:585-91.

12. Brooks R. EuroQol: the current state of play. Health policy. 1996;37:53-72.

13. EuroQol G. EuroQol--a new facility for the measurement of health-related quality of life. Health policy. 1990;16:199-208.

14. Holden MK, Gill KM, Magliozzi MR, Nathan J, Piehl-Baker L.Clinical gait assessment in the neurologically impaired. Reliability and meaningfulness. Physical therapy. 1984;64:35-40.

15. van Swieten JC, Koudstaal PJ, Visser MC, Schouten HJ, van Gijn J. Interobserver agreement for the assessment of handicap in stroke patients. Stroke. 1988;19:604-7.

16. Jo MW, Yun SC and Lee SI. Estimating quality weights for EQ-5D-3Lhealth states with the time trade-off method in South Korea. Value Health 2008;11:1186-9.

17. Kim MH, Cho YS, Uhm WS, Kim S, Bae S-C. Cross-cultural adaptation and validation of the Korean version of the EQ-5D index in patients with rheumatic diseases. Qual Life Res. 2005;14:14016.

18. Kwon S, Park J-H, Kim W-S, Han K, Lee Y, Paik N-J. Health-related quality of life and related factors in stroke survivors: Data from Korea National Health and Nutrition Examination Survey (KNHANES) 2008 to 2014. PloS one. 2018;13:e0195713.

19. Bushnell CD, Reeves MJ, Zhao X, Pan W, Prvu-Bettger J, Zimmer L, Olson D, Peterson E. Sex differences in quality of life after ischemic stroke. Neurology. 2014;82: 922-31.

20. Golicki D, Niewada M, Buczek J, Karlińska A, Kobayashi A, Janssen MF, Pickard AS. Validity of EQ-5D-5L in stroke. Qual Life Res. 2015;24:845-50. 
21. Seong S-S, CC-B, Sung Y-K, Park Y-W, Lee H-S, Uhm W-S, Kim T-W, Jun -J-B, Yoo D-H, Lee O-Y, Bae S-C. Health-Related Quality of Life using EQ-5D in Koreans. J Korean Rheum Assoc. $2004 ; 11: 254-62$

22. Jørgensen HS, Nakayama H, Raaschou HO, Vive-Larsen J, Støier M, Olsen TS. Outcome and time course of recovery in stroke. Part I: Outcome. The Copenhagen Stroke Study. Arch Phys Med Rehabil. 1995;76:399-405.

23. Wood JP, Connelly DM, Maly MR. 'Getting back to real living': A qualitative study of the process of community reintegration after stroke. Clin Rehabil. 2010;24:1045-56.

24. Almborg A-H, Ulander K, Thulin A, Berg S. Discharged after stroke - important factors for health-related quality of life. J Clin Nurs. 2010;19:2196-206.

25. Burton CR. Living with stroke: a phenomenological study. J Adv Nurs. 2000;32:301-9.

26. Hackett ML, Yapa C, Parag V, Anderson CS. Frequency of depression after stroke: a systematic review of observational studies. Stroke. 2005;36:1330-40.

27. Pohjasvaara T, Vataja R, Leppävuori A, Kaste M, Erkinjuntti T. Depression is an independent predictor of poor long-term functional outcome post-stroke. Eur J Neurol. 2001;8:315-9.

28. Kauhanen M-L, Korpelainen JT, Hiltunen P, Brusin E, Mononen H, Maatta R, Nieminen P, Sotaniemi KA, Myllyla VV. Poststroke depression correlates with cognitive impairment and neurological deficits. Stroke. 1999;30:1875-80.

29. Gillen R, Tennen H, McKee TE, Gernert-Dott P, Affleck G. Depressive symptoms and history of depression predict rehabilitation efficiency in stroke patients. Arch Phys Med Rehabil. 2001;82:1645-9.

30. Paolucci S. Epidemiology and treatment of post-stroke depression. Neuropsychiatr Dis Treat. $2008 ; 4: 145$. 
31. Lundström E, Smits A, Terént A, Borg J. Time-course and determinants of spasticity during the first six months following first-ever stroke. J Rehabil Med. 2010;42:296-301.

32. Welmer AK, Widen Holmqvist L, Sommerfeld DK. Location and severity of spasticity in the first 1-2 weeks and at 3 and 18 months after stroke. Eur J Neurol. 2010;17:720-5.

33. Sommerfeld DK, Gripenstedt U, Welmer AK. Spasticity after stroke: an overview of prevalence, test instruments, and treatments. Am J Phys Med Rehabil. 2012;91:814-20.

34. Robinson CA, Shumway-Cook A, Matsuda PN, Ciol MA. Understanding physical factors associated with participation in community ambulation following stroke. Disabil Rehabil. 2011;33:1033-42.

35. Bijleveld-Uitman M, van de Port I, Kwakkel G. Is gait speed or walking distance a better predictor for community walking after stroke? J Rehabil Med. 2013;45:535-40.

36. H Byeon, HW Koh. The relationship between communication activities of daily living and quality of life among the elderly suffering from stroke. J Phys Ther Sci. 2016;28:1450-3.

37. Mazaux J-M, Lagadec T, Panchoa De Sèze M, Zongo D, Asselineau J, Douce E, Trias J, Delair M-F, Darrigrand B. Communication activity in stroke patients with aphasia. J Rehabil Med. $2013 ; 45: 341-6$.

38. Duncan PW, Lai SM, Tyler D, Perera S, Reker DM, Studenski S. Evaluation of proxy responses to the Stroke Impact Scale. Stroke. 2002;33:2593-9.

39. Dorman PJ, Waddell F, Slattery J, Dennis M, Sandercock P. Are proxy assessments of health status after stroke with the EuroQol questionnaire feasible, accurate, and unbiased? Stroke. 1997;28:1883-7.

40. Pickard AS. Agreement between patient and proxy assessments of health-related quality of life after stroke using the EQ-5D and Health Utilities Index. Stroke. 2004;35:607-12. 
41. Williams LS, Bakas T, Brizendine E, Plue L, Tu W, Hendrie H, Kroenke K. How valid are family proxy assessments of stroke patients' health-related quality of life? Stroke. 2006;37:2081-5

42. Carod-Artal FJ, Egido JA. Quality of life after stroke: the importance of a good recovery. Cerebrovasc Dis. 2009;27:204-14.

43. Carod-Artal FJ, Coral LF, Trizotto DS, Moreira CM. Self- and proxy-report agreement on the Stroke Impact Scale. Stroke. 2009;40:3308-14.

44. Bruno A, Akinwuntan AE, Lin C, Close B, Davis K, Baute V, Aryal T, Brooks D, Hess DC, Switzer JA. Simplified modified rankin scale questionnaire: reproducibility over the telephone and validation with quality of life. Stroke. 2011;42:2276-9.

45. Yang J, Jit M, Zheng Y, Feng L, Liu X, Wu JT, Yu H. The impact of influenza on the health related quality of life in China: an EQ-5D survey. BMC Infect Dis. 2017;17:686.

46. Thiem U, Klaassen-Mielke R, Trampisch U, Moschny A, Pientka L, Hinrichs T. Falls and EQ5D rated quality of life in community-dwelling seniors with concurrent chronic diseases: a crosssectional study. Health Qual Life Outcomes. 2014;12:2.

47. McPhail S, Lane P, Russell T, Brauer SG, Urry S, Jasiewicz J, Condie P, Haines T. Telephone reliability of the Frenchay Activity Index and EQ-5D amongst older adults. Health Qual Life Outcomes. $2009 ; 7: 48$. 
Figure 1. Flow chart of subjects involved in the study. 16 patients could not enrolled (absence when telephone interview: 15, refusal to interview: 1). At post-stroke 6 months, total 192 patients were assessed, and 17 patients were excluded (absence when telephone interview: 16, refusal to interview: 1). At post-stroke 12 months, total 106 patients were assessed, and 17 patients were excluded (absence when telephone interview: 13 , refusal to interview: 3 , death: 1 )

Figure 2. Prevalence of worsening problems for each PSC item following 3, 6, and 12 months.

Abbreviations: PSC, PostStroke Checklist; ADL, Activities of Daily Living

A number expressed as a percentage is the percentage of case which means the percentage by selecting the corresponding item from among all the respondents. 